\title{
Sailing the Prestige out to sea. An independent analysis
}

\author{
ANTONIO GARCÍA-OLIVARES ${ }^{1}$, JOSÉ LUIS DE PABLOS ${ }^{2}$ and RAFAEL MADRIGAL ${ }^{3}$ \\ ${ }^{1}$ Institut de Ciències del Mar (ICM-CSIC), Passeig Maritim de la Barceloneta, 37-49, 08003 Barcelona, Spain. \\ E-mail: agarcia@icm.csic.es \\ ${ }^{2}$ CIEMAT, Av. Complutense, 22, 28040 Madrid, Spain. \\ ${ }^{3}$ Maritime Engineering Laboratory (LIM) and Universitat Politècnica de Catalunya (UPC), Carrer de 1'Escar 6-8, \\ 08039 Barcelona, Spain.
}

\begin{abstract}
SUMMARY: The sinking of the supertanker Prestige off the coast of Spain in November 2002 was one of the most devastating oil spills ever worldwide. During any crisis most of the decisions have to be taken with limited information and they can benefit greatly from a rational methodology based on the available information. The main mechanisms involved in oil spill impacts are reviewed and we propose a decision tree based only on scientific criteria and data that are expected to be available in the first moments of an oil spill crisis. In the Prestige crisis, one of the decisions taken was to sail the Prestige out to sea. This paper makes an independent analysis of that decision to illustrate the methodology proposed, which may help decision making in future emergency situations.
\end{abstract}

Keywords: oil spill, response planning, Prestige, operational oceanography, deep sea, Atlantic Ocean.

RESUMEN: CONDUCIENDO AL PRESTIGE MAR ADENTRO. Un ANÁLISIS INDEPENDIENTE. - El hundimiento del petrolero Prestige frente a las costas españolas en noviembre de 2002 ha constituido uno de los vertidos más devastadores producidos en el mundo. Durante una crisis, la mayor parte de las decisiones han de ser tomadas con información limitada y pueden beneficiarse enormemente de una metodología racional que se base en la información disponible. Este artículo revisa los principales mecanismos que afectan al impacto de un vertido de petróleo y propone un árbol de decisión basado sólo en criterios científicos y datos que se puede esperar estarán disponibles en los primeros instantes de una crisis por vertido. En la crisis del Prestige, una de las decisiones tomadas fue la de conducir al barco mar adentro. Este artículo hace un análisis independiente de esa decisión con el fin de ilustrar la metodología propuesta, que puede ayudar a tomar la mejor decisión en futuras situaciones de emergencia.

Palabras clave: vertido de petróleo, plan de respuesta, Prestige, oceanografía operacional, mar abierto, Océano Atlántico.

\section{INTRODUCTION}

In the last 35 years, 5 important accidents have occurred off the coasts of Galicia involving the supertankers Prestige (2002), Aegean Sea (1992), Andros Patria (1978), Cason (1987), and Good Lion (1983). Thus, every 7 years on average an oil spill accident occurs off the Galician coast, and we should expect the next to occur in the next decade.

Supertankers transport daily more than 110 million tons of oil in the world and, according to the ITOPF (International Tanker Owners Pollution Federation), between 1968 and 2000 half of the oil spills into the sea were caused by supertankers and transport ships. In the case of the Prestige, the massive spill, large oil persistence and high economic usage of the Galician coast helped to create a very large impact, estimated to amount to $€ 771$ million (Loureiro et al., 2006).

Ultimately, any accident, incident or crisis has one positive consequence: the lesson learned. In the case of the Prestige oil spill the lesson is still not clear, so we really need to rethink the decisions that were taken during that crisis. In 2003 some authors wrote a letter to Science magazine expressing the opinion that the decisions taken in the management of the Prestige crisis, and in particular the decision to carry the ship out to 
sea, were not the best ones (Serret et al., 2003). Here we analyse that decision retrospectively and establish a simple decision tree based on technical and scientific data for decision making in similar cases.

\section{Definition of the assessment context}

According to White and Molloy (2003) there is a general agreement on the main technical factors that influence the costs of spills. They can be ordered as follows:

1. The persistence of the oil in the environment. Persistent oils have a longer potential impact on the economy, tourism and ecosystems of the affected coast.

2. Weather and sea conditions affecting the spill dispersion. The dominant winds and currents may drive the main fraction of the spill onto the coast or out to the deep sea, leading to a variety of impacts. In this regard, the season of the year may be important.

3. Amount spilled and rate of spillage.

4. Geographical, biological and economic characteristics of the area affected.

5. Effectiveness of clean-up. A quick intervention of a fleet of cleaner ships may be able to confine the spill around the ship, minimizing the long-term impacts. A clean-up of an already contaminated coast may have very different short-term and long-term costs.

\section{Persistence of the oil}

The international compensation regime for oil spills only applies to spills of "persistent" oil. Whilst this term is not precisely defined in any of the conventions, the International Oil Pollution Compensation Funds (IOPC Funds) have developed guidelines which are widely accepted. Under these guidelines, an oil is considered non-persistent if at the time of shipment at least $50 \%$ of the hydrocarbon fractions, by volume, distil at a temperature of $340^{\circ} \mathrm{C}\left(645^{\circ} \mathrm{F}\right)$ and at least $95 \%$ of the hydrocarbon fractions, by volume, distil at a temperature of $370^{\circ} \mathrm{C}\left(700^{\circ} \mathrm{F}\right)$ when tested in accordance with the American Society for Testing and Materials (ASTM) Method D86/78 or any subsequent revision thereof. Oils which are normally classified as persistent include crude oils, fuel oils, heavy diesel and lubricating oils. Non-persistent oils include gasoline, light diesel oil and kerosene.

Persistent oil can be carried hundreds of miles in the form of scattered tarballs by winds and currents. The tarballs vary in diameter from several metres to a few centimetres and may be very difficult to detect visually or with remote sensing techniques. The specific gravity of a particular No. 6 fuel oil can vary from 0.95 to greater than 1.03 . Thus, spilled oil can float, suspend in the water column or, as the lighter hydrocarbons evaporate, become heavier and sink. Small changes in water density may dictate whether the oil will sink or float. Floating oil in a high-sediment environment (rivers, beaches) could potentially sink once it picks up sediment, resulting in subsurface tarballs or tarmats. These oils can occasionally form an emulsion, but usually only slowly and after a period of days. Because of its high viscosity, beached oil tends to remain on the surface rather than penetrate sediments. Light accumulations usually form a "bathtub ring" at the high-tide line; heavy accumulations can pool on the beach. Shoreline cleanup can be very effective before the oil weathers, becoming stickier and even more viscous. Natural degradation rates for these heavy oils are very slow. The oil may persist on beaches for months to years.

The main properties that affect the fate of spilled oil at sea are specific gravity (its density relative to pure water, often expressed as ${ }^{\circ}$ API or API gravity); distillation characteristics (its volatility); viscosity (its resistance to flow); and pour point (the temperature below which it will not flow). In addition, the wax and asphaltene content influence the likelihood that the oil will mix with water to form a water-in-oil emulsion. Oils that form stable water-in-oil emulsions persist longer at the water surface.

The relation between API degrees and density is the following:

$$
{ }^{\circ} \mathrm{API}=(141.5 / \mathrm{SG})-131.5
$$

where SG is the relative density (specific gravity) of the oil.

Most oils have SG values lower than 1 and it is therefore difficult for them to reach the density needed to sink (about 1.026 at the Prestige wreckage point) even if they lose their volatile fraction by evaporation. Sinking occurs mainly after incorporation into the oil of particles from bottom sediments and it may occur only very close to the coast. The International Tanker Owners Pollution Federation (ITOPF) has proposed a simple empirical model of oil persistence based on the properties of different oil types. For this purpose, it classifies the most commonly transported oils into four main groups, roughly according to their specific gravity (see Table 1). Having classified the oils, the expected rate at which the volume of oil at the sea surface decreases can be estimated. These four groups are shown in Figure 1, where account is also taken of the competing process of emulsification which, for most oils, leads to an increase in volume.

Group I oils (non-persistent) tend to dissipate completely through evaporation within a few hours and do not normally form emulsions. Group II and III oils can lose up to $40 \%$ by volume through evaporation but, be-

TABLE 1. - Kinds of oil.

\begin{tabular}{|c|c|c|}
\hline Group & Density & Examples \\
\hline Group I & less than 0.8 & gasoline, kerosene \\
\hline Group II & $0.8-0.85$ & gas oil, Abu Dhabi Crude \\
\hline Group III & $0.85-0.95$ & $\begin{array}{l}\text { Arabian light crude, North Sea } \\
\text { crude oils (e.g. Forties) }\end{array}$ \\
\hline Group IV & greater than 0.95 & heavy fuel, Venezuelan crude oils \\
\hline
\end{tabular}




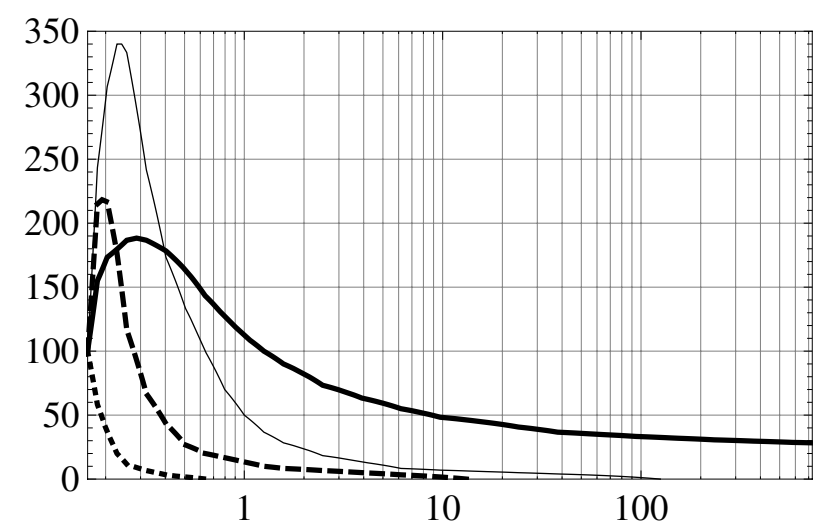

FIG. 1. - Volume of oil and water-in-oil emulsion remaining on the sea surface as a percentage of the original volume spilled versus time (days) for oils belonging to: Group 1 (dotted line), Group 2 (dashed line), Group 3 (thin line) and Group 4 (thick line). Adapted from the ITOPF web page (www.itopf.com/marine-spills/fate/models/).

cause of their tendency to form viscous emulsions, there is an initial volume increase as well as a curtailment of natural dispersion, particularly in the case of Group III oils. Group IV oils (the group of the Prestige oil) are very persistent due to their lack of volatile material and high viscosity, which preclude both evaporation and dispersion. As can be observed in Figure 1, in the case of a heavy fuel, $25 \%$ of the initial oil is expected to remain at the surface one year after the release. The main processes contributing to the weathering of the floating oil on this time scale are: (i) vertical turbulent dispersion of particulate oil in the water column, (ii) photo oxidation and (iii) biodegradation.

Emulsification and photo oxidation are responsible for the transformation of heavy fuel slicks in very dense and viscous layers, which are fragmented in the form of "tarballs". In the Prestige case, the water content of the fuel aged at sea reached $60 \%$ with a kinematic viscosity of $0.1 \mathrm{~m}^{2} \mathrm{~s}^{-1}$ at $15^{\circ} \mathrm{C}$, and a measured density of $1.01 \mathrm{~kg} \mathrm{~L}^{-1}$, close to that of the sea water but slightly lower. The original slicks of heavy fuel oil (hundreds of tons each) drifting at sea broke into pieces, segregated into patches (up to a few metres in diameter), pancakes (0.1-1 $\mathrm{m}$ in diameter), discs (up to $10 \mathrm{~cm}$ in diameter) and finally pellets up to a few centimetres in diameter (Daniel et al., 2004; Carracedo et al., 2006).

Given that persistent oils are not affected by weathering on the scale of months, in these kinds of spill shipping out the supertanker to the deep sea will probably not minimize the impact on the shoreline unless the characteristic drift time of the oil is several years or more - a situation that is not frequent due to mean marine currents, sea horizontal turbulence and wind stress.

\section{Climatic and oceanographic factors affecting the dispersion}

The fate of the spill is very dependent on the daily variable climatic and oceanographic conditions. Many models represent the floating oil as a set of Lagrangian drifters advected by the combined influence of surface currents and wind speed. The wind drag is introduced into simulations as a percentage of wind velocity, the windage factor, which is added to the drift produced by the local marine currents field. The local drift velocity in the slick can then be calculated by the following expression:

$$
v=u_{x}+\frac{\tau_{x}}{f}, u_{y}+\frac{\tau_{y}}{f} \cong\left(u_{x}+0.03 U_{x}, u_{y}+0.03 U_{y}\right)
$$

where $u\left(u_{x}, u_{y}\right)$ is the surface current speed, $U\left(U_{x}, U_{y}\right)$ is the surface wind speed and 0.03 is a windage factor. At deep-sea locations, tidal currents can be neglected when compared with the above mechanisms.

In Equation (1), the two critical parameters are $u$ and $U$. To obtain $u$, operational oceanography forecasts should be the first choice if they are available because they give a suitable representation of the turbulent current field.

Operational oceanography $(\mathrm{OO})$ can be defined as the activity of systematic and long-term routine measurements of the seas and oceans and atmosphere, and their rapid interpretation and dissemination. Important products derived from operational oceanography are:

- nowcasts providing the most usefully accurate description of the present state of the sea including living resources;

- forecasts providing continuous forecasts of the future condition of the sea as far ahead as possible;

- hindcasts assembling long-term data sets which will provide data for description of past states, and time series showing trends and changes (EUROGOOS 2011).

Operational oceanography proceeds usually by the rapid transmission of observational data-to-data assimilation centres. There, powerful computers using numerical forecasting models process the data. The outputs from the models are used to generate data products, often through intermediary value-adding organizations. Examples of final products include prediction of ocean currents and ocean climate variability. The final products and forecasts must be distributed rapidly to industrial users, government agencies and regulatory authorities. In Europe, the European Global Ocean Observing System is one of the most important systems oriented towards these purposes that are currently available (www.eurogoos.org).

The wind field $U$ is normally predicted by national meteorological institutions for as much as the next 5 days. For estimations in the scale of months to one year, past wind fields obtained from hindcasts or, more simply, wind rose frequencies, may be used to represent the probability of occurrence of different wind classes on the time scale of interest.

In the case of a spill of fuel belonging to group 1 or 2 in Figure 1, persistence times are of the order of one week or less. In these cases, meteorological data 
will be normally available for the whole integration period and should be assimilated and used by the dispersion model in order to predict the slick drift over the period. OO systems use this approach and, when they are available, which is the usual case in a developed country under normal conditions, it is recommended to use them as a first step for predicting whether most of the spill will impact the coast in less than one week (the typical predictability horizon of an initial conditions simulation with assimilation of wind data).

Surface oceanic currents are variable turbulent phenomena and also have a predictability horizon limited to several days due to their strong coupling with wind fields. In the case of more persistent spills, such as those belonging to Group 4, no forecast covering the period of interest, between months and years, is available. In these cases, operational oceanography forecasts should be used, if they are available, to predict whether a large fraction of the spill will reach coastal areas within a few days after the accident. For longer time scales, the same models can be used but in the framework of statistical modelling of long-term dispersion. In these models, wind and current fields have to be probabilistically represented. OO systems or similar models can be fruitfully used in the simulation, since in these models the characterization of the turbulent current field is state-of-the-art and based on hindcast reconstructions of similar past scenarios. In addition, $\mathrm{OO}$ systems usually include models for coastal mechanisms, such as waves, tides and oil interaction with sediments.

If this kind of hindcast is not available, an alternative could be to use wind probability taken from the wind rose of historical data for the nearest coast. Monthly frequency wind roses are available from historical data for the main villages of the Iberian coast and they should also be available for many other coasts. Similarly, seasonal mean current velocities observed in the past can be used and the small-scale current variability can be modelled with a scale-dependent eddy diffusivity parameter.

\section{Amount of oil spilled}

The amount of oil spilled is an important parameter but the cost of cleanup is not directly proportional to this magnitude. Smaller amounts could have a higher cost per ton spilled. For example, the study of historical events by Monnier (1994) established that spills of under 10 metric tons had a cleanup cost of $\$ 345000$ per ton at that date whereas spills of over 50 tons had a cost of $\$ 12000$ per ton.

\section{Cleanup}

As discussed by Etkin (2000), the type of oil spilled significantly affects cleanup costs. Cleanup costs of spills by oil type based on this author are shown in Table 2 .
TABLE 2. - Per unit oil spill cleanup cost by oil type (US\$2009). Based on Etkin (2000).

\begin{tabular}{lc}
\hline Oil type & Cost $(2009$ \$US/t $)$ \\
\hline No. 2 diesel fuel & 2940 \\
Light crude & 5435 \\
No. 4 fuel & 30440 \\
No. 5 fuel & 29544 \\
Crude & 9236 \\
Heavy crude & 10880 \\
No. 6 fuel & 21597 \\
\hline
\end{tabular}

No. 2 diesel fuel and light crude oil spills are significantly less expensive to clean up than spills of more persistent oils.

Mechanical containment and recovery are used, when possible, to remove some of the oil, but these efforts often show little gain, since light oils begin to evaporate and dissolve very quickly after hitting the water surface. Gasoline spills are not represented in Table 2 because they often require little or no cleanup, since by the time responders can get to the spill scene most of the product has evaporated or dissolved. The response usually deals solely with mitigating the toxic and flammable hazards of this type of incident rather than actual product removal.

Spills of more persistent products require more sophisticated cleanup strategies, which can include dispersant application when appropriate, or mechanical and manual recovery. Depending on the location and degree of shoreline impact, spills of persistent oils generally require the most expensive spill response operations. Responses to spills of persistent oils that are near shorelines can result in prolonged and laborious shoreline cleanup responses, if offshore dispersant or mechanical containment and recovery operations are ineffective or incomplete. However, when weather conditions allow, the effectiveness of mechanical recovery is fairly high for persistent oils and avoids the beaching of a large fraction of the fuel.

Oil spills that impact shorelines are considerably more expensive to clean up than ones that can be dealt with offshore, especially if they involve manual cleaning.

\section{Geographical, biological and economic characteristics of the area affected}

The type of shoreline involved is also a critical factor. A coast with a large economic, recreational or ecological value, such as the Galician coast or the Alaskan coast in the Exxon Valdez accident, must be recovered for their normal uses, normally under the pressure of media, politicians and local people. This implies a more complete response to the question "how clean is clean".

For example, in 1999 the average cost of cleanup per metric ton (Etkin, 2000) was of the order of $\$ 850$ in Mexico, $\$ 910$ in Chile, $\$ 8600$ in the European Union, \$23118 in Norway and \$25614 in US. 
The degree of shoreline oiling is a important factor in determining the cost. Etkin found a linear correlation between cost per ton and $\mathrm{km}$ of shoreline oiling:

$$
\begin{gathered}
\text { Cost }(\$ / \mathrm{t})=38.42 \times(\mathrm{km} \text { of shoreline })+4830.1 \\
\text { with: } \mathrm{R}^{2}=0.948(\mathrm{US} \$ 1999)
\end{gathered}
$$

In theory an in-port oil spill ( $\$ 16540$ per ton) is more expensive than an offshore $(\$ 10918 / \mathrm{t})$ but we must take into account the amount of oil that could be recovered in-port and the possibility that the weather may prevent recovery of the oil offshore. Also, ecological impacts may result effects of slicks floating offshore on birds and marine species, as well as their effects on coastal protected areas.

\section{THE PRESTIGE CASE}

On Wednesday 13 November 2002, the singlehulled oil tanker Prestige sent a distress call offshore in the region of Cape Finisterre, 50 kilometres from the coast of Galicia, Spain. The tanker was carrying $76972 \mathrm{t}$ of heavy fuel oil (Wene, 2005) which had been loaded in St Petersburg (Russia). The vessel developed a reported 30 degree starboard list whilst on passage in heavy seas and strong winds and hence requested partial evacuation of the crew. Twenty-four of the twenty-seven crew members were evacuated by helicopter while the captain, the first mate and the chief mechanic stayed onboard. The engine was damaged and the ship went out of control and drifted according to the weather conditions. Aerial observation revealed an oil leak at sea.

All night long, the tug boats Ria de Vigo, Alonso de Chaves, Charuca Silveira and Ibaizabal I from SASEMAR (Sociedad de Salvamento y Seguridad Maritima), the Spanish organization in charge of sea rescue and pollution control, tried to take the oil tanker in tow. The emergency towing system of the ship did not work and the different attempts failed. In the end, the Prestige was taken in tow by a ship from the company Smit Salvage on 14 November. It was towed to the northnorthwest all day. Once the vessel was secured, the Spanish authorities denied the vessel a sheltered area of refuge, instead ordering that it be towed towards the Northeast Atlantic. The master stopped the Prestige's engines on 15 November, fearing that excessive vibration would aggravate the structural damage to the hull. At that moment, the ship was forced over 35 metres on the right side. After a 30-metre crack had been detected in the hull, further requests were made for a place of refuge, but the Spanish authorities ordered the vessel to be towed in a westerly direction, defending its action not to grant a port of refuge by stating that the Prestige's draught was too large to enter the port of A Coruña. The order was disobeyed and subsequently Spain declared that the vessel, having been towed south, was outside its territorial waters and therefore out of its jurisdiction.

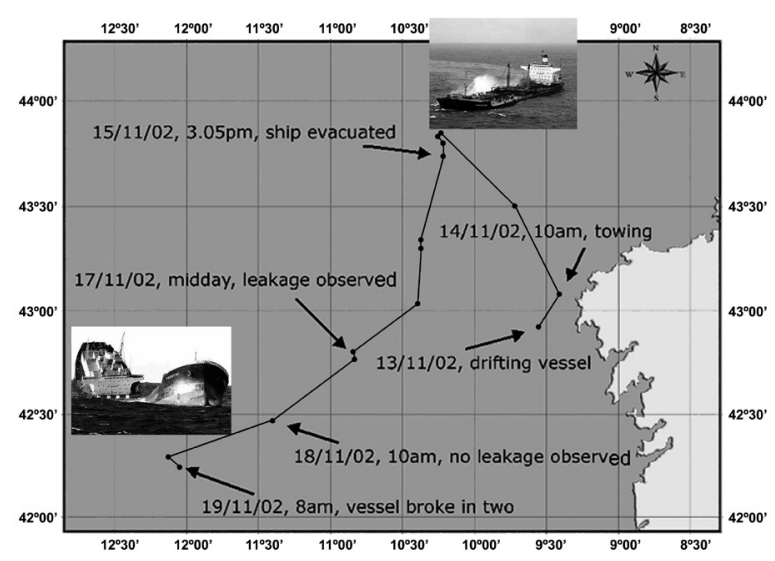

FIG. 2. - Trajectory followed by the Prestige tanker between the first emergency call to the day of the sinking. Taken from Christophe Rousseau, Cedre. Bulletin d'Information du Cedre $\mathrm{N}^{\mathrm{o}} 18,1^{\text {st }}$ semester 2003.

On 16 November, the towing was turned to the south-west to avoid Portuguese waters. The Portuguese authorities refused entry of the vessel within its Exclusive Economic Zone (200 nautical miles), with the result that the Prestige broke into two parts in international waters on 19 November, at $42^{\circ} 15 \mathrm{~N}$ and $12^{\circ} 08 \mathrm{~W}$, about 130 nautical miles off the Spanish coast, westsouthwest of Cape Finisterre. At noon, the stern part of the Prestige sank into 3500 metres of water. The bow part followed at about 4 p.m. (Fig. 2).

A hypothesis provided by the Prestige's classification society, the American Bureau of Shipping (ABS), suggests that the incident was a result of a hull structural failure in combination with 6 days of heavy weather. It is thought that a weakened section in the starboard side shell or supporting frame initiated the hull failure, and this weakness together with wave impact resulted in an opening of the side shell below the water surface (Wene, 2005).

This oil spill was unique in many respects, first with regard to drift, as it was the first time that a spill contaminated 6 countries, and also regarding the long persistence of the oil, the highly significant effect of the slick break-up process, and how this effect influenced the choice of response measures and techniques offshore and then inevitably onshore. The French Centre of Documentation, Research and Experimentation on Accidental Water Pollution (CEDRE) documented from the very beginning the impacts produced by the Prestige accident and maintain an online database with information on this and other important accidents (www.cedre.fr).

The viscosity of the Prestige's crude oil increased steadily as it divided slowly but gradually into patches and smaller slicks that became increasingly difficult to see and track from the spotter planes as the tar balls broke down into even smaller tar balls that either floated on the water surface or tended to drift around in the upper layers of the water column throughout the Bay of Biscay. 
When the tanker broke up, it was clear that seabirds and mammals would run the risk of being oiled by the heavy fuel oil from the Prestige. Galician coasts are a waypoint, as it were, for migratory birds and they are also a haven for international bird sanctuaries, including RAMSAR. Galicia also harbours colonies of otters, dolphins and sea turtles. Oiled birds started being washed up on the beaches only a few days after the accident. Galician authorities and NGOs involved in the rescue plan were assisted on the spot by international experts. A major problem during the Prestige spill was that there was no pre-set plan for caring for wildlife. Although the autonomous government of Galicia set up an organization to delegate powers to the organizations working in the field, no unit was in charge of co-coordinating the efforts and communication. Consequently, despite the willingness of responders, the teams worked in isolation most of the time, with the result that many of the birds taken to the city of Pontevedra arrived too late to be saved. A contingency plan designed in advance is highly recommended in order to achieve an efficient response both from the technical and the financial points of view.

\section{Physical and chemical properties and weathering of the Prestige oil}

The oil transported in Prestige's tanks was a residual product from oil distillation that had been processed by means of thermal breaking of large hydrocarbon chains and a final addition of light hydrocarbons. Its names are heavy oil type M-100 (the Russian name), heavy fuel number 2 (the French name) and number 6 fuel oil (the American name). In the following the American name will be used.

This fuel oil is a dense, viscous fluid produced by blending heavy residual oils with a lighter oil (often No. 2 fuel oil) to meet viscosity and pour point specifications. When spilled on water, No. 6 fuel usually spreads into thick, dark-coloured slicks that can contain large amounts of oil. Oil recovery by skimmers and vacuum pumps can be very effective early in the spill. According to the NOAA fact sheet on No. 6 fuel oil, (Hazardous Materials Response and Assessment Division), very little of this viscous oil is likely to disperse into the water column and only $5-10 \%$ is expected to evaporate within the first hours of a spill. Even at high wind speeds, usually over $70 \%$ of No. 6 fuel oil will persist as floating or beached oil for a week or longer.

An approximate correlation for the density of No. 6 fuel oil and temperature is (Marcos et al., 2004):

$$
\rho\left(\mathrm{kg} \mathrm{m}^{-3}\right)=1016.3-1.4262 T
$$

and for the oil viscosity the correlation is:

$$
\begin{gathered}
\mu(\mathrm{kg} / \mathrm{m}-\mathrm{s})=102.8-6.6267 T+0.1515 T^{2}-0.0012 T^{3}, \\
20<T<50, \\
\mu(\mathrm{kg} / \mathrm{m}-\mathrm{s})=1000-193.95 T+13.114 T^{2}-0.2933 T^{3}, \\
0<T<20,
\end{gathered}
$$

where $T$ denotes the oil temperature in ${ }^{\circ} \mathrm{C}$.

The fuel density changes from 945 to $1,012 \mathrm{~kg} \mathrm{~m}^{-3}$ as the temperature falls from $50^{\circ} \mathrm{C}$ to $2.6^{\circ} \mathrm{C}$, whereas viscosity increases by approximately three orders of magnitude from 0.215 to $579 \mathrm{~kg} / \mathrm{m} \mathrm{s}$. The buoyancy of the oil is always positive due to its $3.5 \%$ difference in density from Atlantic sea water at the same temperature.

During the Prestige crisis, some studies accepted the hypothesis that oil tarballs followed the wind direction with a windage between $1 \%$ and $4 \%$. Good results were obtained by applying a windage of $2.8 \%$ of the wind velocity (Montero et al., 2003). However, Carracedo et al. (2006) found that a windage of $1.5 \%$ for surface-drifting oil and $0 \%$ for subsurface oil (below $0.5 \mathrm{~m}$ ) allowed it to obtain a better fit to observations.

Slicks were located at sea by aerial surveillance managed by the French Maritime Prefect. Additionally, from 18 November, SASEMAR produced a daily position chart of the observed pollution. Three main oil release events were reported from the Prestige tanker: the first one, hereinafter the "first oil spill", was a mobile, continuous release from the initial vessel position on 13 November to the sinking position on 19 November, which amounted to 6000 metric tons; the second one, hereinafter the "main spill", took place in the sinking area from 19 to 30 November, and released an unknown amount greater than 20000 t; A third release from the sunken wreckage until the blocking of the leakages in the hull (29 January 2003) accounted for about $4000 \mathrm{t}$ (Montero et al., 2003).

The simulation of Carracedo et al. (2006) reproduced a single plume of oil, which agrees with the most intense of the observed plumes reaching the Finisterre Cape on 17 November. However, the sailing effect and wind current transport were not sufficient to explain the oil distribution observed in the ENVISAT image (Fig. 3 ), with two plumes of oil painting the ship's course, black areas located southerly. These two plumes were consistent with oil drifting only with the subsurface currents, suggesting that larger (more buoyant) tarballs tended to remain in the surface layer whereas smaller tarballs were mixed downwards (Elliott, 1986). The two plumes were formed because of the presence of two products of different density which could be related to the dual composition of the No. 6 fuel oil in the tanker. The predictability of the fate of the main spill in the long term has proven to be very sensitive to accurate knowledge of the daily wind field and current system. A good system of meteorological data assimilation is crucial to the former. Ocean currents are not normally monitored daily and had to be inferred from oceanographic models.

The mean seasonal surface circulation in the area has been described by Ruiz-Villarreal et al. (2006). During the autumn-winter season, SW winds are dominant and these induce a poleward current of 10 to 20 $\mathrm{cm} / \mathrm{s}$ flowing over the Portugal and Galicia slope and coastal downwelling. This was the mean situation at 


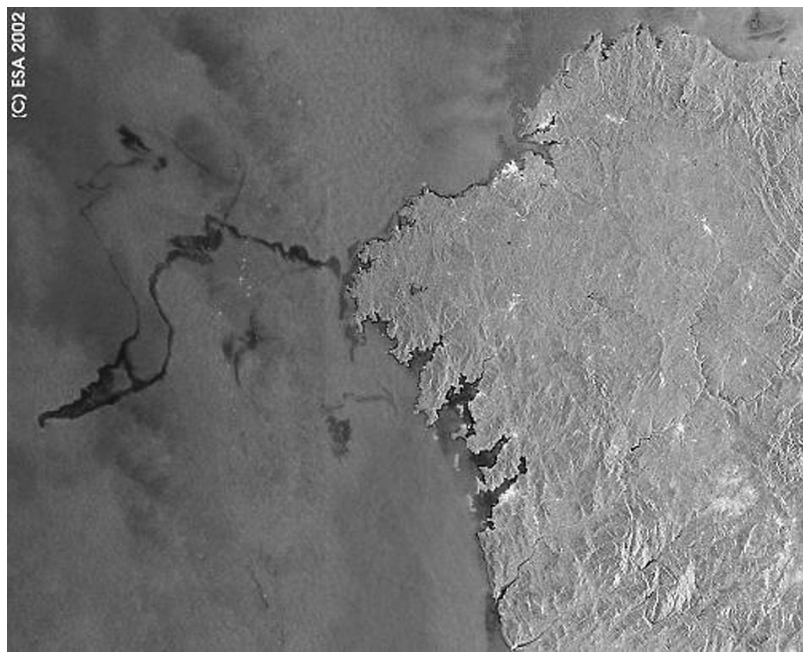

FIG. 3. - November 17, 2002. ASAR-ENVISAT ESA Satellite image showing the wake of fuel oil.

the Prestige wreckage. However, the large variability of the winds and associated currents are apparent in the following description of the upwelling-downwelling events following this date (Ruiz-Villarreal et al., 2006): one upwelling pulse between late November and early December; some days of upwelling dominance in January and February followed by downwelling conditions that lasted almost a month from mid-February; one upwelling pulse at the end of March followed by several days of southerly winds during April and a succession of weak upwelling pulses from May to July, interrupted by downwelling pulses; and intense upwelling pulses at the end of June.

The mean dominant wind component in November, SW winds, and the northward slope current along the Galician and Cantabrian coasts were responsible for the drift of most of the fuel of the main spill in this direction (Fig. 3). However, NW winds are frequent in the area during autumn and winter (Martí Ezpeleta et $a l ., 1998)$, generally associated with deep polar lows centred on the British Isles following the westerlies zonal movement into Northern Europe. These situations were responsible for the movement of some oil spots onto the Cantabrian Coast on December 13, 2002.

Daniel et al. (2004), using the Mercator model and the Modèle Océanique de Transport d'Hydrocarbures (MOTHY) used by Méteo France, were able to predict with good accuracy the trajectory of the main spots that impacted the Cantabria Coast with some days of anticipation. However, in practical cases the predictability window is limited by the accuracy of the meteorological predictions available, which normally have a horizon of a few days.

Several institutions performed chemical analyses of the Prestige oil. Saturated hydrocarbons, resins, naphthalenes, and near 50\% polycyclic aromatic hydrocarbons (PAHs) gave the fluid a great stability and toxicity. From the fluid dynamics point of view, a fraction of between $20.6 \%$ and $34.7 \%$ of the fuel will not flow in conditions below $5^{\circ} \mathrm{C}$ due to the high percentage of resins and asphaltenes.

Irwin (1997) presents the chemical composition of a typical No. 6 fuel oil. His table can be used to independently estimate the fraction of volatile hydrocarbons (HC) contained in this kind of fuel.

According to Stolzenbach, we consider a $\mathrm{HC}$ to be volatile if its boiling point is under $270^{\circ} \mathrm{C}$ or the number of carbons in its molecule is lower than 16. This fraction of hydrocarbons is the one expected to evaporate in normal conditions in times of the order of one week after the oil release (Stolzenbach et al., 1977, pp. 4-37). With this criterion, we find the following percentages of volatile components: $0.18 \%$ of volatile n-paraffins, $0.63 \%$ of volatile isoparaffins, $10.2 \%$ of volatile cycloparaffins, $1.9 \%$ of benzenes, $2.1 \%$ of tetralins and indenes, $2 \%$ of dinaphthenobenzenes, $1.5 \%$ of benzothiophene and $14.4 \%$ of pentane, making a total of $32.8 \%$ of volatile components.

The complementary fraction, about $67 \%$ to $70 \%$, corresponded to persistent oil. For this fraction, the only effective weathering mechanism on the annual scale is expected to be vertical turbulent mixing. This mechanism is a sink for surface oil, as shown in the weathering curves in Figure 1, but it is a source of hydrocarbons that are able to drift along subsurface layers into coastal zones, where they may interact more easily with suspended sediments.

\section{Oil recovered and source term}

Figure 4, based on the CEDRE information on the Prestige accident (CEDRE, 2002a, 2002b), shows the accumulated metric tons of emulsified oil and algae recovered offshore during the months following the spill. Between $35 \%$ and $40 \%$ of the quantity recovered was oil. As can be observed, the total volume collected in the first three months was $51000 \mathrm{t}$, which is about the volume spilled. Thus, the volume reduction predicted by Figure 1 (for a fuel of the Group 4) clearly underestimates the real persistence of the Prestige spill. This may be partly due to the fact that Figure 4 includes

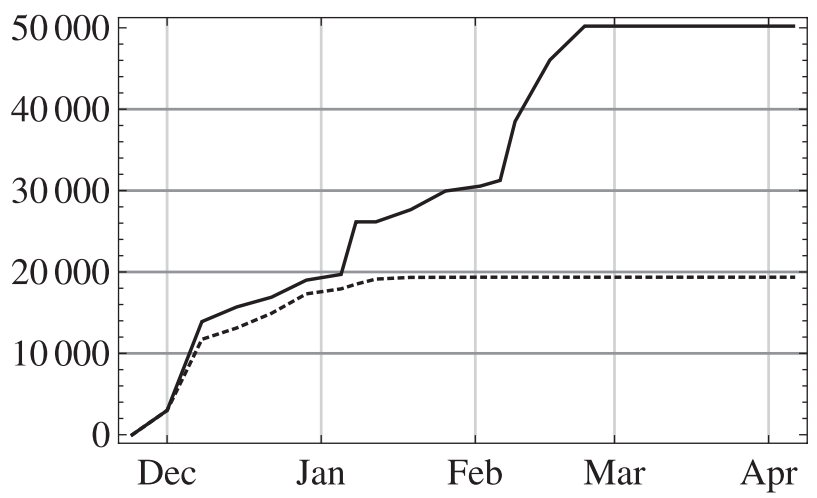

FIG. 4. - Accumulated amount of emulsified oil and algae (metric tons) recovered at sea as a function of time (continuous line) and amount recovered by oil recovery vessels (dashed line). Adapted from www.cedre.fr. 
TABLE 3. - Distribution of quantities (tons) estimated jointly by Le Cedre and the Spanish Institution for Sea Security (Sesemar).

\begin{tabular}{lrr}
\hline & Contaminated materials (t) & Net fuel (t) \\
\hline Decontamination ships, unloading in Spain & 14946 & 5381 \\
Decontamination ships, unloading in France & 1081 & 346 \\
Decontamination ships, unloading in Portugal & 160 & 61 \\
Total decontamination ships & 16187 & 5787 \\
Fishers, unloading in Spain & 37993 & 17097 \\
Fishers, unloading in France & 3963 & 504 \\
Total fishers & 55563 & 17601 \\
Total recovered at sea & 67883 & 23388 \\
Recovered onshore Galicia & 21855 & 12219 \\
Recovered onshore Asturias + Cantabria + Basque Country & 89738 & 3497 \\
Total recovered onshore in Spain & 3657 & 15716 \\
Recovered onshore France ZDO & 21813 & 585 \\
Recovered onshore France ZDSO & 25470 & 3490 \\
Total recovered onshore France & 115208 & 4075 \\
Total recovered onshore & & 19791 \\
Evaporated, dispersed at sea & & 3150 \\
Weathered onshore & & 1575 \\
Settled, weathered on the continental platform & & 1000 \\
Total naturally disappeared & & 5725 \\
Recovered from the wreckage & & 13600 \\
Remaining in the wreckage & & 1700 \\
\hline
\end{tabular}

emulsified oil and also algae and floating wastes aggregated with the oil. Given that the total aggregate has to be recovered from the sea, Figure 1 can be used only as an optimistic prediction or lower bound. To obtain an upper bound for the persistence of one heavy oil, a possible approach is to assume that the persistent fraction of the oil (67\% to $70 \%$ in the Prestige case) remains with no volume reduction in the year following the spill.

Table 3 shows the most likely values for the total fuel recovered and degraded naturally. These quantities were estimated jointly by CEDRE and the Spanish Institution for Sea Security (SASEMAR). CEDRE estimated that 115000 metric tons of sand and emulsified oil were recovered onshore, of which about $19800 \mathrm{t}$ were estimated to be oil. The total oil recovered and lost by weathering is estimated to be $48904 \mathrm{t}$. The ship carried nominally $77000 \mathrm{t}$, even though it is not an infrequent practice to carry a larger cargo than declared. The difference between these two quantities is $28096 \mathrm{t}$. Part of this fraction is non-recovered oil and the rest is oil that remained in the ship after the wreck. Thus, the best estimate for the lower bound of the total spilled is $48904 \mathrm{t}$.

If, according to the final extraction report made by the Repsol Company, 15300 t remained in the sunken ship (see values at the end of the Table 3) then the quantity spilled must have been 61700 t. Thus, the quantity spilled ranges between 48904 and $61700 \mathrm{t}$ and about 23388 t of oil, i.e. $37 \%$ to $47.8 \%$ of the total spill, was recovered offshore.

A precise estimation of the source term as well as the oil fractions recovered offshore and onshore is not possible even some years after the accident, so these quantities obviously cannot be known in the first moments of the accident. In the Prestige case, the mobilization of fishers in the Cantabrian Sea was exceptionally efficient, but it is expected to vary widely in different scenarios. For this reason, in the simulation of a real-time estimation of costs that follows, we use $50000 \mathrm{t}$ as a reasonable estimate of the quantity spilled and $30 \%$ to $46 \%$ as a reasonable range for the source fraction that is expected to be recovered offshore.

\section{Costs and decision criteria}

Cleanup costs on a per-ton basis decrease significantly with increasing amounts of oil: Smaller spills are often more expensive on a per-ton basis than larger spills because of the costs associated with setting up the cleanup response, bringing in the equipment and labour, and bringing in the experts to evaluate the situation (Etkin, 1999). However, two of these aspects will reduce costs per ton only on a continuous flat coast. On the very rocky and tortuous Galician coast, the bringing of equipment, labour and experts had to be separate and partially independent tasks, such as those that would apply to a set of many independent spill cleanup events. This is probably the reason for the failure of the Etkin model of 2000 (Etkin, 2000) to provide realistic cleanup costs when applied to our scenario: the costs obtained are two-orders of magnitude less than the real costs reported by Loureiro et al. (2006), which was $€ 228$ million (including only coast cleaning). The reason for the failure of the Etkin-2000 model is essentially the factor 0.01 that it introduces to account for 
the decrease of the per-ton cost when the spill is greater than 34000 t, as it was in the Prestige accident.

The 1999 model of the same author does not use so strong a reduction factor, but only a reduction of $86 \%$ in the cost for spills larger than $15000 \mathrm{t}$, which works much more realistically in our case. This model seems more appropriate to the Galician coast, which has a large economic and recreational usage, requiring high levels of response to the question "how clean is clean".

The spill correction factor $s=1+\operatorname{sp}(m)$ (where $m$ is the mass spilled) used in Etkin's two models (Etkin, $1999,2000)$ is given by means of tables for $s p$ with step discontinuities between different categories of $m$. Both models could be fitted to a function of the following form:

$$
s= \begin{cases}c & m<m_{0} \\ (a+b f(m)) / m & m>m_{0}\end{cases}
$$

where $c$ is a constant value for small spills, $a$ is an initial mobilization cost, $b f(m)$ is a unit cost that is assumed to depend on $m$ and $b$ is a constant. Etkin's first model (Etkin, 1999) fits approximately with the model $c=1.8$, $m_{0}=30, a=50.8, b=0.11$ and $f(m)=m^{0}=1$. Etkin's second model (Etkin, 2000) fits better with the model $c=1.8, m_{0}=30, a=0.52, b=16.3$ and $f(m)=m^{-0.651}$. The main difference is that the first model uses a constant unit cost $b$ and the second one uses a unit cost decreasing with $m$ as $m^{-0.65}$.

After the introduction of the euro, it seems more realistic to use a European mean cost of $€ 8600$ per ton instead of using national costs. For the case of Spain, the cost per ton used by the Etkin model of 2000 (Etkin, 2000) is unrealistically low: it assigns to Spain a labour cost 20 times lower than that of the European mean. This was correct 30 years ago but now Spain is very close to the European mean in most economic indicators.

From the total oil spilled (48900 to 61700 t), 19000 to $23000 \mathrm{t}$ was recovered in the first three months by the joint work of specialized boats and the fishery fleet (González et al., 2006, CEDRE, 2002b) and 20000 to $27000 \mathrm{t}$ was recovered onshore. Etkin (2000) observed that some past costs of offshore recovery were $26 \%$ to $55 \%$ lower than the cost associated with recovering oil on the shoreline. For this reason, we used the factor (0.46) suggested by Etkin (2000) for offshore dispersant technique as a suitable factor for calculating the total cost of the offshore oil recovery by the fishery fleet.

Let us assume that in the first moments of the accident $50000 \mathrm{t}$ of oil was spilled from the wreckage, that the combined offshore recovery efforts achieve an efficiency of $46 \%$, and that the remaining $54 \%$ reaches the coast. The 1999 Etkin model can then be used in the Prestige case with the following parameters (the costs are in 1999 US dollars): $\$ / \mathrm{T}$
- Major shoreline oiling, implying a $127 \%$ increase of the previous cost ( $o i=1.27)$.

- Heavy fuel spilled, implying a $40 \%$ increase of the previous cost $(t y=0.40)$.

- Cleanup strategy based on manual and mechanical operations, implying a $61 \%$ increase of the previous cost $(s t 1=0.61)$, for $54 \%$ of the oil $($ on $=0.54)$.

- Offshore recovery, implying a $73 \%$ of decrease of the previous cost $(s t 2=-0.73)$, for $46 \%$ of the oil $(o f=0.46)$.

- More than 15000 t spilled, implying a 86\% reduction of the previous cost ( $s p=-0.86)$.

- Total spilled fuel assumed: $t s=50000 \mathrm{t}$.

- The inflation rate between 1999 and end of 2004: $16.1 \%($ in=1.161)

- Dollars to euro conversion rate: $d 2 e=0.8$

The expression used to calculate the cost is the following:

$$
\begin{aligned}
& c=\{\text { on }[d 2 e \times \operatorname{in} \times \operatorname{lo}(1+o i)(1+t y)(1+s t 1)(1+s p)]+ \\
& +o f[d 2 e \times i n \times l o(1+o i)(1+t y)(1+s t 2)(1+s p)]\} t s
\end{aligned}
$$

The total cost obtained for the cleanup is $€ 176.5$ million, 23\% lower than the real cost of coastal cleanup reported some years after the accident: $€ 228$ million (Loureiro et al., 2006). If a more conservative fraction for offshore recovery is assumed, $30 \%$, then the total cost increases to $€ 214.6$ million, which is close to the real cost. However, the first recovery fraction is closer to the one observed.

The model uses only the limited information available in the first moments of the accident and provides a good order of magnitude of the cost expected for the cleanup work. However, in the Prestige case the total economic cost for the region affected ranges between 4 times more than the coastal cleanup cost, $€ 770.6$ million (Loureiro et al., 2006), and 5 times more (Wene, 2005). This factor 4 to 5 is derived from the cost of extraction of the oil remaining in the sunken tanker at $3500 \mathrm{~m}$ depth, waste treatment and recycling, payments to the volunteers, compensation, and trade and environmental losses.

The experience in the Basque community suggests that a good organization of the fishery fleet along the whole coast may be able to recover between $30 \%$ and $50 \%$ of a spill of persistent heavy fuel oil (Cedre, 2002 b, González et al., 2006) with a cost roughly one order of magnitude lower than the onshore recovery.

According to Carracedo et al. (2006), the Prestige spilled about $6000 \mathrm{t}$ of fuel between 13 November and the final break-up and sinking on 19 November. Let us imagine that on 14 November the vessel had been towed to some near port instead of out to sea. The Prestige draught was $14 \mathrm{~m}$. Therefore, the near ports of refuge with sufficient depth to allow the towing of the tanker by an expert harbour pilot are Ferrol-San Cibrao (17 m), Vigo (17 m) and A Coruña (16 m; shelter, 19 $\mathrm{m})$. Assuming that $6000 \mathrm{t}$ is a conservative estimation 
of the oil spilled during this towing at the spill rate observed in the first moments and that this oil all contaminates the port area, Etkin's model (2000) can be used to estimate the cost of port cleanup.

The expression used is the following:

$$
\begin{gathered}
C_{e}=C_{u} A I e \\
\text { with } C_{u}=C_{l} \text { toms and } C_{l}=\operatorname{rl} C_{n}
\end{gathered}
$$

where $C n$ is the general cost per unit spilled taking into account the economic characteristics of the site $(\$ 8600$ per ton for Europe), $l$ and $r$ are local and regional modifiers (here taken as 1 ); $t$ is the type of oil modifier (here 0.71 for No. 6 fuel oil); $o$ is the length of affected coast modifier (here a few tenths of kilometres are assumed, implying $o=0.54) ; m$ is the modifier for the technology employed (here mechanical technology is assumed, implying $m=0.92$ ); $s$ is the spill size modifier (here two values were used: 0.05 , recommended for spills larger than $3400 \mathrm{t}$ and 0.15 , recommended for those smaller than $3400 \mathrm{t}$ ); $A$ is the quantity spilled (here $6000 \mathrm{t}$ ); $I$ is the inflation factor between 1999 and 2005 (here 1.17) and $\boldsymbol{e}$ is the dollar-euro conversion factor (here 0.8).

The result obtained was between $€ 1$ million and $€ 2.7$ million, depending on the $s$ modifier chosen. Thus, according to Etkin's models based on historical data, and the hypotheses exposed above, the expected cost of cleaning up the port and surrounding coast is two orders of magnitude lower than the expected cost of a major impact on the seashore by $50000 \mathrm{t}$ of heavy fuel.

\section{Ecological risks}

Ecological damage cannot be reduced to monetary costs. However, it is one of the main factors to be taken into account in the evaluation of the consequences of an oil spill, so an independent quantification of this kind of risk can be very useful in any response planning.

In our particular case, 5 natural parks in Galicia and on the Cantabrian coast have shorelines: the Atlantic Islands National Park (Pontevedra); the Corrubedo dunes and lagoons of Carregal and Vixán (A Coruña); the Oyambre dunes; the Liencres dunes; and the Santoña, Victoria and Joyel marshes. The first one is a national park; the second and last are covered by the Ramsar Convention (The Convention on Wetlands of International Importance, especially as Waterfowl Habitat); and the third and fourth are important places of bird migration.

A simple way to quantify ecological risk is to define ranges for tolerable and non-tolerable risk ratings. A risk rating $r$ is defined as the following product: $r=p$ $i$, where $i$ is a numerical index of impact and $p$ is the probability of that impact. In our context, a simple approach would be to consider 6 kinds of impact degree with their corresponding numerical value-negligible $(i=1)$, minor $(i=2)$, moderate $(i=3)$, major $(i=4)$, critical $(i=5)$ and catastrophic $(i=6)$ - and to use the beaching probability obtained from the Lagrangian model to define $p$. The ecological damage usually consists of many independent impacts. These impacts have their own contamination thresholds after which the damage becomes serious, and these thresholds have different likelihoods of occurring. For this reasons, a "vectorial" use of the risk expression $r=p \times i$ may be more appropriate. In this regard, the following sequential methodology can be followed:

- Identify the presence of ecologically sensitive targets in different coastal segments. For the case of the heavy fuel released by the Prestige, its behaviour over time has been described in Sections 1 and 2, and a list of ecological targets specially sensitive to this fuel can be found from the research literature to be: (a) protected shorelines whose ecological dynamics should be maintained as unperturbed as possible (this includes many coastal national parks and RAMSAR sanctuaries); (b) abundance of seabirds; (c) presence of marine mammals with coastal habitats; (d) high concentrations of molluscs with ecological value; (e) high concentrations of plankton; (f) indigenous populations of specialist sediment dwellers; (g) presence of mangrove swamps or salt marshes; and (h) presence of fragile marine communities (e.g., corals, seagrass ecosystems). In our case, we can identify segments of the coastline with presence of targets in the (a) and (b) categories.

- Assign an impact value $i$ to the hypothetical loss of the ecological value of the target, e.g. with the scale from $i=1$ (minor) to $i=6$ (catastrophic) proposed above. In the case of the segments containing the two identified coastal parks, we can assign the value $i=6$ to the loss of ecological value of both parks.

- Define a threshold value of contamination $(t)$ for which the ecological value of the target may start to be in danger. This is the most complex task and it could require detailed biological research on the species response to the oil contamination. Let us assume here that $t=35 \mathrm{t} / \mathrm{km}$ is the threshold for the two coastal parks we are considering. This figure implies that, if the slick is $5 \mathrm{~cm}$ high and between 1 and $5 \mathrm{~m}$ wide, its length along the coast would be between 700 and 140 $\mathrm{m}$, affecting $70 \%$ to $14 \%$ of the shoreline, respectively, and probably affecting sea birds and marine mammals of the park.

- Use the threshold value $t$ to define the event "oiling $(\mathrm{t} / \mathrm{km})$ larger than $t$ ", with probability $p$. Use the Lagrangian simulation to obtain this probability $\mathrm{p}_{\mathrm{k}}(\mathrm{t} /$ $\mathrm{km}>t$ ). Here $\mathrm{k}$ is an index to number the target.

- Calculate $r_{k}=p_{k} i_{k}$ for this target $k=1$, and repeat the procedure above for every target $k=2,3 \ldots$ An integrated risk could be defined from the set of $r_{k}$ values obtained, for instance: $r=\operatorname{Max}\left(\left\{r_{k}\right\}\right)$, where Max designs the maximum of the set of values $\left\{r_{k}\right\}$. If a range of unaccepted tolerance is defined for $r$ (e.g. those events with $r \geq 1$ are considered unacceptable) then the final ecological risk can be valued. This choice $r \geq 1$ would imply that events that place in danger the ecological 
value of a target with the maximum valuation $(i=6$ in our illustration) are not allowed to have a probability $1 / 6$ or larger.

Other ways to define the groups of events corresponding to the different $p$ and $i$ values are possible, and this analysis is only illustrative of the methodology. The precise criteria for obtaining $i$ values should not be arbitrary but should be based on studies on the biological consequences of the possible loss of the real target present at the coast and, ideally, should be agreed by society. A way to give more weight to specific ranges of $p$ values (or $i$ values), if it is needed, is to use (in step 5) a more general expression to calculate the risk, such as $r_{k}=\mathrm{f}\left(p_{k}\right) \times \mathrm{g}\left(i_{k}\right)$, where $\mathrm{f}$ and $\mathrm{g}$ are functions of $p$ and $I$, respectively. In risk assessment, risks typically range over several orders of magnitude, and this degree of variation is better captured on a logarithmic scale. For this reason, in some applications, it could also be useful to define not only two ranges for $r$ (in our example $r<1$, acceptable; $r \geq 1$, unacceptable) but several intermediate logarithmic ranges of increased significance between a threshold risk value considered "negligible" and the highest range, called "unacceptable". For instance: $\mathrm{r}<7.710^{-4}$, negligible; $7.710^{-4}-4.610^{-3}$, very small; $4.610^{-3}-2.810^{-2}$, small; $2.810^{-2}-1 / 6$, medium; $1 / 6-1$, high; $r \geq 1$ unacceptable risk. Ecological risks so quantified should be considered in conjunction with economic costs as important inputs in the final response to the crisis.

\section{DISCUSSION OF THE PRESTIGE CASE AND DECISION TREE}

In the case of spills belonging to Groups I and II, as well as in the first days of spills belonging to Group IV, the ESEOO project may be used as an excellent source of information and models in the case of a new occurrence off the Spanish coasts. This project (see Ruiz-Villarreal et al., 2006, Sotillo et al., 2008) was set up after the Prestige accident and it has generated several useful operational oceanography products. In particular, operational daily current forecasts, predicting several days in advance, are publicly available on the web www.eseoo.org for the Galician, Cantabrian, Basque and part of the Mediterranean Coasts.

In the case of spills belonging to Groups III and IV a few days after the accident, oceanic currents and wind fields cannot be modelled by running ocean general circulation models from initial conditions. Statistical simulation using the variability of the fluid fields should therefore be considered.

Below we discuss only spills belonging to Group $\mathrm{IV}$, as these are the ones that are potentially most dangerous. We take the Prestige case as an example to test the proposed methodology.

This methodology has been implemented in the Prestige scenario in two ways: (i) the hindcast Approach, which uses a Lagrangian model forced with one annual hindcast of currents and winds (many OO systems include this kind of prediction as one of their products); and (ii) the simple approach, in which no $\mathrm{OO}$ system is assumed to be operating and only a wind rose and a simplified mean picture of the oceanic circulation is assumed to be available.

In both approaches, a likely trajectory for a spill can be computed from Equation (1) by integrating the expression for different Lagrangian points over a period of time $\mathrm{T}$. This period $\mathrm{T}$ would be in the order of magnitude of the persistence time of the fuel, which can be obtained from Figure 1 (optimistic estimation) or from the hydrocarbon fractions of the fuel (conservative estimation). Given that every particle represents a fraction of the oil remaining in the water, the number of particles would be recalibrated over time to represent the quantity of oil assumed to remain at that time. When a particle drifted into the modelled shoreline, it would be removed from the set of drifting particles, which would generally decrease with time. This method would be analogous to that proposed by Sotillo et al. (2008).

To implement the hindcast approach, in this work the Regional Ocean Modelling System (ROMS) was used with a mean horizontal resolution of $6.6 \mathrm{~km}$. Surface forcing inputs used in the model are hourly data with a resolution of $30 \mathrm{~km}$, provided by MeteoGalicia (the Regional Meteorological Office of Galicia) and obtained from the Fifth-Generation NCAR/Penn State Mesoscale Model (MM5). The model specifications are described in detail by Ferrer et al. (2009). Hindcasts of the years 2007 and 2008 obtained with this model have been used in this work.

Figure 5 shows the current field produced by the model in the first day of simulation. One thousand particles were randomly released every 5 days during one year from 3 rectangles placed in front of the Galicia coast, in the region where the Prestige sent its first SOS call. The rectangles are limited by the following vertices of longitude and latitude: Zone 1: $(-10.5,42.45),(-10.5,42.95),(-10.0,43.1)$ and $(-10.0$, 42.55); Zone 2: $(-10.5,43.25),(-10.5,43.75),(-10.0$, 43.9) and $(-10.0,43.35)$; Zone 3: $(-10.0,43.55)$, $(-10.0,44.05),(-9.487,44.20)$ and $(-9.5,43.65)$ and they are also shown in the figure.

In the simple approach, the different wind intensity and direction classes are stochastically used with an occurrence probability derived from their observed frequencies. The integration was implemented 40 times from initial drifter positions stochastically distributed in Zone 2 shown in Figure 5. Different predictions are obtained in different runs for the number of oil particles that reach the shoreline, due to the stochastic use of the wind frequency charts.

The integration time was one year. Oceanic circulation in the area was assumed to be dominated by the Portugal current during typical upwelling seasons (spring and summer) and typical downwelling seasons (autumn and winter) (Villarreal et al., 2006). Hyperbolic streamlines around the coast were assumed to have zero divergence, an intensity of around $0.15 \mathrm{~m} / \mathrm{s}$ 


\section{Surface Currents}

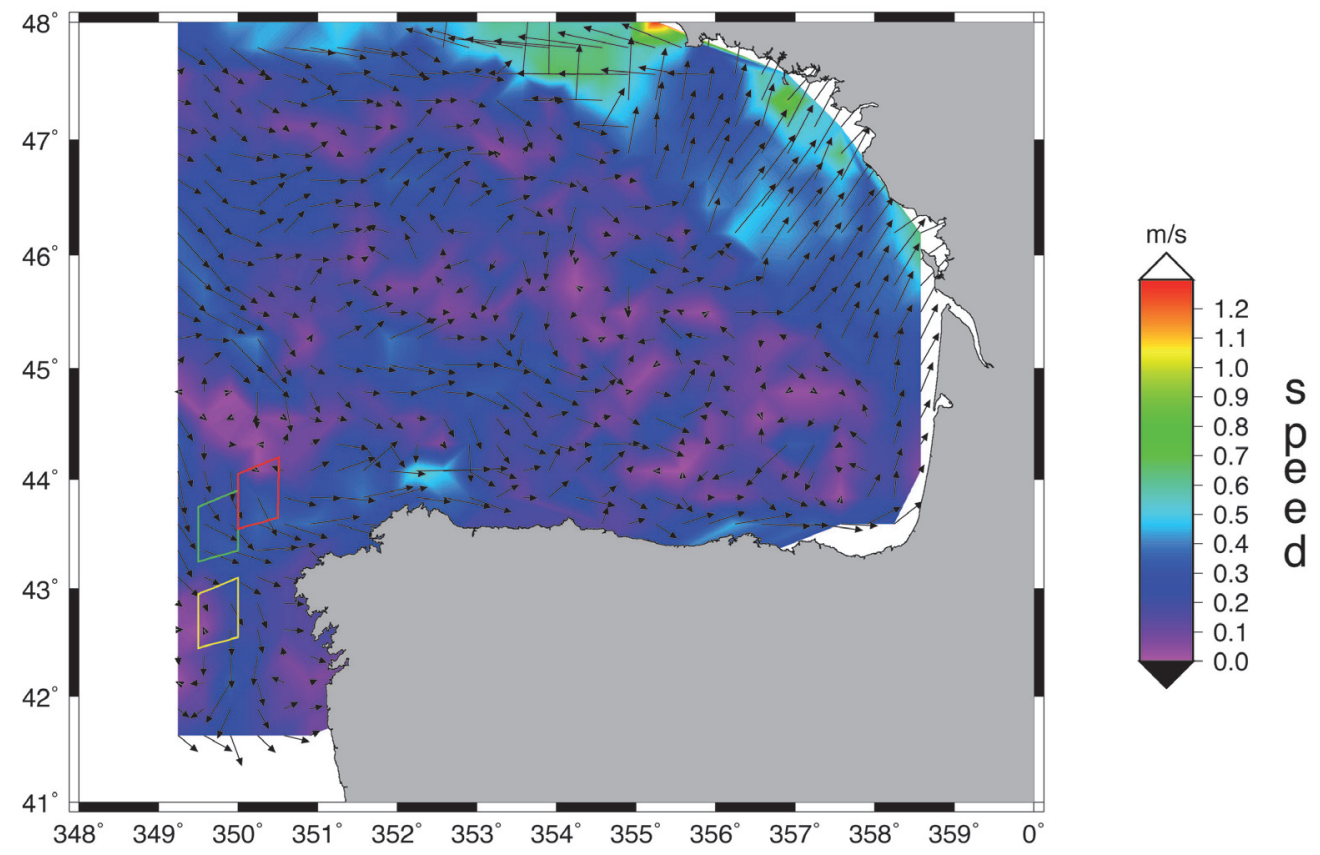

FIG. 5. - Current field on the first day of the Lagrangian simulation and location of the zones of release of the 1000 tracers. Zones 1,2 and 3 correspond to the red, green and orange polygons, respectively.

and directed to the northeast far from the coast during the autumn-winter seasons and the opposite direction during the spring-summer seasons. This value was obtained by extrapolating the geostrophic velocities at 40 , 30 and $20 \mathrm{~m}$ depth in the Prestige wreck location as they were measured by the ADCP deployed at a mooring line from 29 March to 12 May 2003 (Villarreal et al., 2006, Table 3).

Note that a typical seasonal current is a simplification and the system is subject to event variability and turbulent eddies. This variability was modelled with an eddy diffusivity parameterization that uses the Okubo (2001) empirical dependence of K with the scale:

$$
K=2.0610^{-4} L^{1.15}
$$

where $L$ is the space scale of the problem (m) and $K$ has units of $\mathrm{m}^{2} / \mathrm{s}$.

To model the wind variability in the area in the simple approach, we used the annual wind rose obtained on the coast of El Ferrol, Galicia by the Spanish Ports institution and available online at <www.puertos.es $>$. Figure 6 shows the wind rose used, which corresponds to 2004. A mean persistence time of 3 days was assumed for each wind class. This simplistic assumption is one of the main limitations of the simple approach, since the wind persistence may vary widely with the meteorological situation, being greater than 3 days in stable situations with a high North Atlantic Oscillation (NAO) index and smaller during the passage of Atlantic fronts.
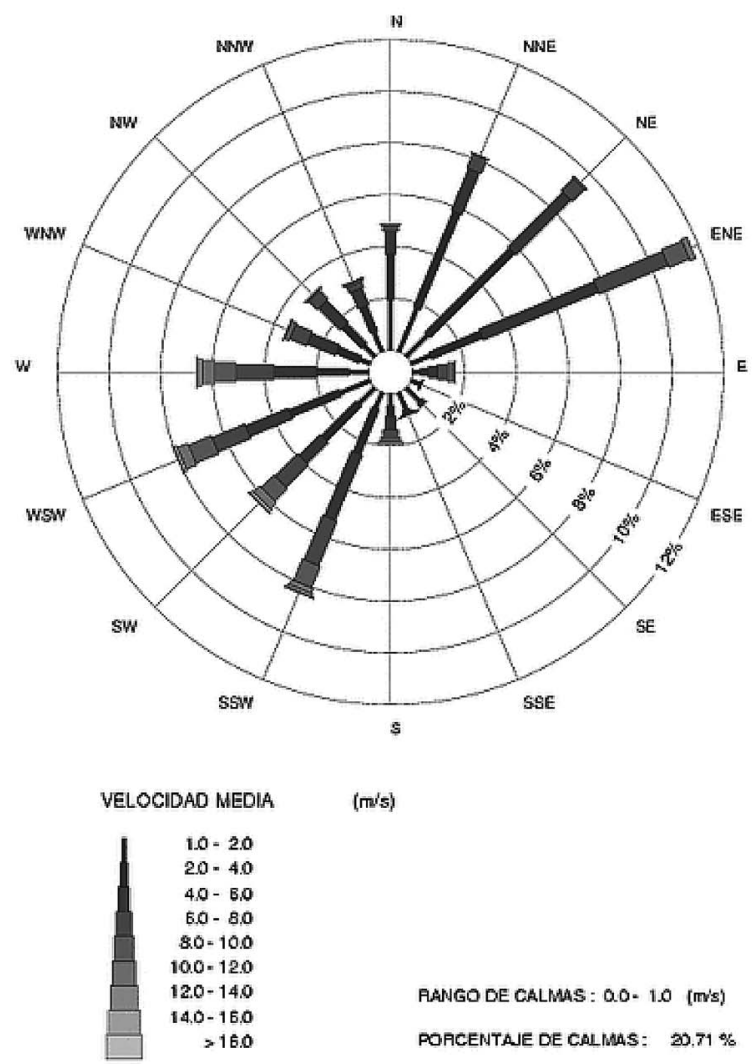

FIG. 6. - Wind Rose for the mean wind velocity at the El Ferrol coast in 2004. Obtained from the Puertos del Estado web page (www.puertos.es) in the menu "Oceanografía y Meteorología". 
Taking now into account the persistence curve (group 4 in Fig. 1), we have two approaches: the optimistic one says that the oil weathering follows the curve shown in Figure 1; The conservative one says that $70 \%$ of the fuel persists on the sea in the first year. In both cases, a fraction of $30 \%$ of the spill is assumed to be recovered offshore and $70 \%$ is allowed to drift for one year.

The number of drifters remaining in movement is scaled with the persistence factor to obtain the fraction of the initial spill that remains active. The number of drifters beached over the period can be used to estimate the volume fraction that affects the shoreline. To estimate the shoreline length affected, the slick is assumed to be $5 \mathrm{~cm}$ high and to form a layer of $1 \mathrm{~m}$ width when beached. With these assumptions, the slick area corresponding to any drifter may be translated to a shoreline length affected to feed the Etkin model. We emphasize that the objective is to quickly estimate the order of magnitude of the impact.

Figure 7 shows the distribution of percentages of the initial volume beached in the period for the conservative persistence hypothesis when the hindcast approach is used (dashed line bars) and when the simple approach is used (full line bars) for the current and wind annual fields. The results correspond to particles released from Zone 2. The frequency of no beaching events (12\% in the hindcast approach; $4 \%$ in the simple approach) is not showed in the histograms. The last frequency class includes events with the maximum possible fraction: $49 \%$ of the initial volume beached, that is, $70 \%$ of volume not recovered multiplied by $70 \%$ of persistent fraction gives $49 \%$ of final volume. To these quantities we must add the $30 \%$ that is assumed to be recovered offshore.

In the conservative hindcast prediction the distribution is bimodal: most frequent events accumulate in the zero (frequency 12\%) and 0-7\% events (frequency $13 \%$ ) and in the impact events between $28 \%$ and $42 \%$ of the initial spill (frequency $20+30=50 \%$ ). In the optimistic prediction, the distribution is also bimodal but the two probabilities and the two modal values are closer: 0.23 for $0-6 \%$ events and 0.33 for events between $12 \%$ and $17 \%$ of the initial spill respectively.

The initial spill from the Prestige was previously estimated in the range 48904 to 61700 t. If we use $19701 \mathrm{t}$ for the total oil recovered onshore (see Table 3 ), it is equivalent to $32 \%$ to $40 \%$ of the initial spill. Thus, the real beaching observed in the Prestige crisis can be considered an event belonging to the main peak of the bimodal distribution displayed in Figure 7 for the hindcast conservative prediction.

Taking the hindcast conservative case in Figure 7 as a reference, the affected shoreline length ranges between 0 and $48 \mathrm{~km}$ for the first set of events, with probability 0.25 , and between 193 and $290 \mathrm{~km}$ for the second set of events, with probability 0.5 .

The simple approach also predicts an approximately bimodal distribution and the global beaching predicted

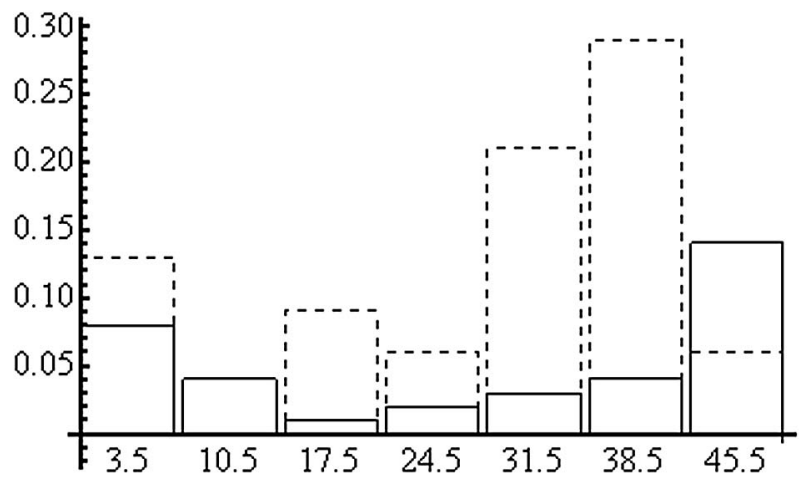

FIG. 7. - Percentage of the initial volume that is beached in one year in the conservative persistence hypothesis according to the hindcast approach (dashed line bars) and to the simple approach (continuous

line bars) respectively. Frequencies are normalized to one.

is in the same order of magnitude as the one predicted by the complex model. Mean values range between $10 \%$ and $26 \%$ of the initial volume spilled for the optimistic and conservative hypotheses, respectively. The standard deviations of these two parameters are $7.7 \%$ and $20 \%$ respectively. However, beaching times tend to accumulate in the first month in the complex approach, and in the first 9 months in the simple approach. This means that the simple approach underpredicts the integrated beaching, as is apparent in Figure 7, due to weathering losses. This is probably because this approach oversimplifies the variability of the fluid fields. For this reason, the simple approach must be consider less reliable, especially for estimating beaching times.

The conclusion of this first step of the methodology is that due to the large persistence of the fuel and to the seasonally oscillatory character of the coastal currents, the quantity of fuel that is expected to reach the coast is an important fraction of the quantity spilled. Beaching events of $26 \%$ to $48 \%$ of the initial release have a probability of 0.5 in the conservative estimation. The resultant frequencies are very dependent on the release area. In addition, our simulations suggest that Zone 1 favours the frequency of beaching in the Cantabrian area, Zone 3 favours the beaching on the Atlantic coast of Galicia and Zone 2 is an intermediate situation.

These results suggest that an increase in the number of years used in the hindcast could greatly improve the precision of the statistics and, thus, the reliability of the results. This would imply the possibility of making Lagrangian simulations with hindcasts of the season where the spill occurs of many different past years. Having this information available in $\mathrm{OO}$ systems can be very useful for applying this methodology.

The second step would be to quantify the ecological risk associated with the presence of protected areas. Table 4 shows the predictions of the most complex model for the different frequencies of tons of oil per kilometre beached in the areas surrounding the two protected areas considered. These frequencies were calculated for releases coming from the three zones shown in Figure 5. In order to obtain enough statistics, 
TABLE 4. - Frequencies of different beaching classes for the Atlantic Islands National Park coast and for the Santoña marsh Ramsar park, according to the predictions of the complex model, when the particles are released from Zones 1, 2 and 3, respectively.

\begin{tabular}{|c|c|c|c|}
\hline & Frequency Zone 1 & Frequency Zone 2 & Frequency Zone 3 \\
\hline \multicolumn{4}{|c|}{ Atlantic beaching $\left(\mathrm{t} \mathrm{km}^{-1}\right)$} \\
\hline $0-3.5$ & 0.02 & 0.042 & 0.10 \\
\hline $3.5-35$ & 0.07 & 0.14 & 0.19 \\
\hline $35-85$ & 0.06 & 0.12 & 0.14 \\
\hline $85-130$ & 0.08 & 0.03 & 0.02 \\
\hline $130-173$ & 0.06 & 0.03 & 0 \\
\hline $173-216$ & 0.02 & 0.01 & 0.01 \\
\hline $216-259$ & 0.03 & 0 & 0 \\
\hline $259-302$ & 0.02 & 0 & 0 \\
\hline \multicolumn{4}{|c|}{ Cantabria beaching $\left(\mathrm{t} \mathrm{km}^{-1}\right)$} \\
\hline $0-3.5$ & 0.002 & 0.028 & 0.03 \\
\hline $3.5-35$ & 0.008 & 0.028 & 0.08 \\
\hline $35-65$ & 0.01 & 0.02 & 0.04 \\
\hline $65-98$ & 0.00 & 0.02 & 0.08 \\
\hline $98-130$ & 0 & 0.01 & 0.02 \\
\hline $130-163$ & 0 & 0 & 0.01 \\
\hline $163-195$ & 0 & 0 & 0 \\
\hline $195-228$ & 0 & 0.02 & 0.02 \\
\hline
\end{tabular}

TABLE 5. - Estimation of the ecological risk for: (a) the Atlantic Islands National Park area and (b) the Santoña marsh Ramsar park area.

\begin{tabular}{|c|c|c|c|}
\hline & Zone 1 & Zone 2 & Zone 3 \\
\hline \multicolumn{4}{|c|}{ Atlantic Islands National Park } \\
\hline$p_{1}(t / k m>35)$ & 0.27 & & \\
\hline$i_{1}$ & $\begin{array}{c}6 \\
\text { catastrophic }\end{array}$ & $\begin{array}{c}6 \\
\text { catastrophic }\end{array}$ & $\begin{array}{c}6 \\
\text { catastrophic }\end{array}$ \\
\hline$r_{1}=p_{1} i_{1}$ & 1.62 & 1.14 & 1.02 \\
\hline \multicolumn{4}{|c|}{ Santoña marsh Ramsar park } \\
\hline$p_{2}\left(\mathrm{t} \mathrm{km}^{-1}>35\right)$ & 0.011 & 0.07 & 0.17 \\
\hline$i_{2}$ & $\begin{array}{c}6 \\
\text { catastrophic }\end{array}$ & $\begin{array}{c}6 \\
\text { catastrophic }\end{array}$ & $\begin{array}{c}6 \\
\text { catastrophic }\end{array}$ \\
\hline$r_{2}=p_{2} i_{2}$ & 0.07 & 0.42 & 1.02 \\
\hline$r=\operatorname{Max}\left(\left\{r_{1}, r_{2}\right\}\right)$ & $\begin{array}{c}1.62 \\
\text { unacceptable }\end{array}$ & $\begin{array}{c}1.14 \\
\text { unacceptable }\end{array}$ & $\begin{array}{c}1.02 \\
\text { unacceptable }\end{array}$ \\
\hline
\end{tabular}

we chose a target segment of $50 \mathrm{~km}$ including the Atlantic Island National Park and the Corrubedo Dunes Ramsar Park in Coruña, and another 50-km segment centred on the Santoña marsh Ramsar park (Cantabria). Table 5 shows the values obtained for $p, i$ and $r$ when the methodology described in the previous section is applied. As can be observed, with the tolerance adopted in Section $2.4(\mathrm{r} \leq 1)$, the risk of impact on the coastal parks would be considered unacceptable in this example. Of course, the conclusion may change if the conditions defining the $i$ values and the tolerance range for $r$ are less strict. These definitions are not exclusively a scientific matter, but also one of political and social consensus.

The third step would consist in estimating the order of magnitude of the shoreline cleanup costs and the costs of offshore recovery. To this end, Etkin's models $(1999,2000)$ can be very useful, when applied sensibly, because they provide reasonable estimations for real accidents. In addition, these models only require data that can be obtained in real time, such as spill size, fuel type, and economic parameters of the region. Pro- vided that the order of magnitude of the coastal oiling has been estimated with a Lagrangian calculation such as the one proposed above, the impact evaluation can be implemented with relatively simple calculations. An alternative way to model the economic costs of the Prestige accident was proposed by Wirtz et al. (2007). This approach requires detailed economic information of the region, which could be not quickly available in a crisis situation, but it may be a good complement to the approach proposed here in a second phase, when the urgency of taking the most critical decisions has decreased.

If the Etkin model is used with the $48 \%$ estimation of beaching provided by the upper bound of the second peak of probability in Figure 7, that is, a beaching of $24000 \mathrm{t}$ and $240 \mathrm{~km}$ of coast affected, the cost estimated is $€ 137$ million, which is lower than the costs calculated previously to the Lagrangian simulation, but still in the order of magnitude of the cost really incurred ( $€ 228$ million).

Thus, in the particular case of the Prestige crisis, the use of the present methodology would have allowed the authorities to conclude that: (i) the oiling of some hundred kilometres of coast has a probability of about 0.5 in the most conservative estimation if the main zone of release is 1 or 2 ; and (ii) the cleanup cost associated with this kind of event is two orders of magnitude greater than that associated with quickly confining the tanker in a refuge port.

Three ports in the Finisterre area have draughts that could be appropriate for this purpose: A Coruña $(16 \mathrm{~m}$; 19 m shelter), Ferrol-San Cibrao (17 m) and Vigo (17 $\mathrm{m})$. The main vessel incidents that may take place in a port are (i) collision with another vessel, (ii) grounding, (iii) fire/explosion, (iv) structural failure and (v) impact with wharves (Lenting and Pratt, 1998). Probabilities of these events can be estimated from historical cases such as those Lenting and Pratt (1998) describe for the New Zealand coast. In our analysis of the Pres- 


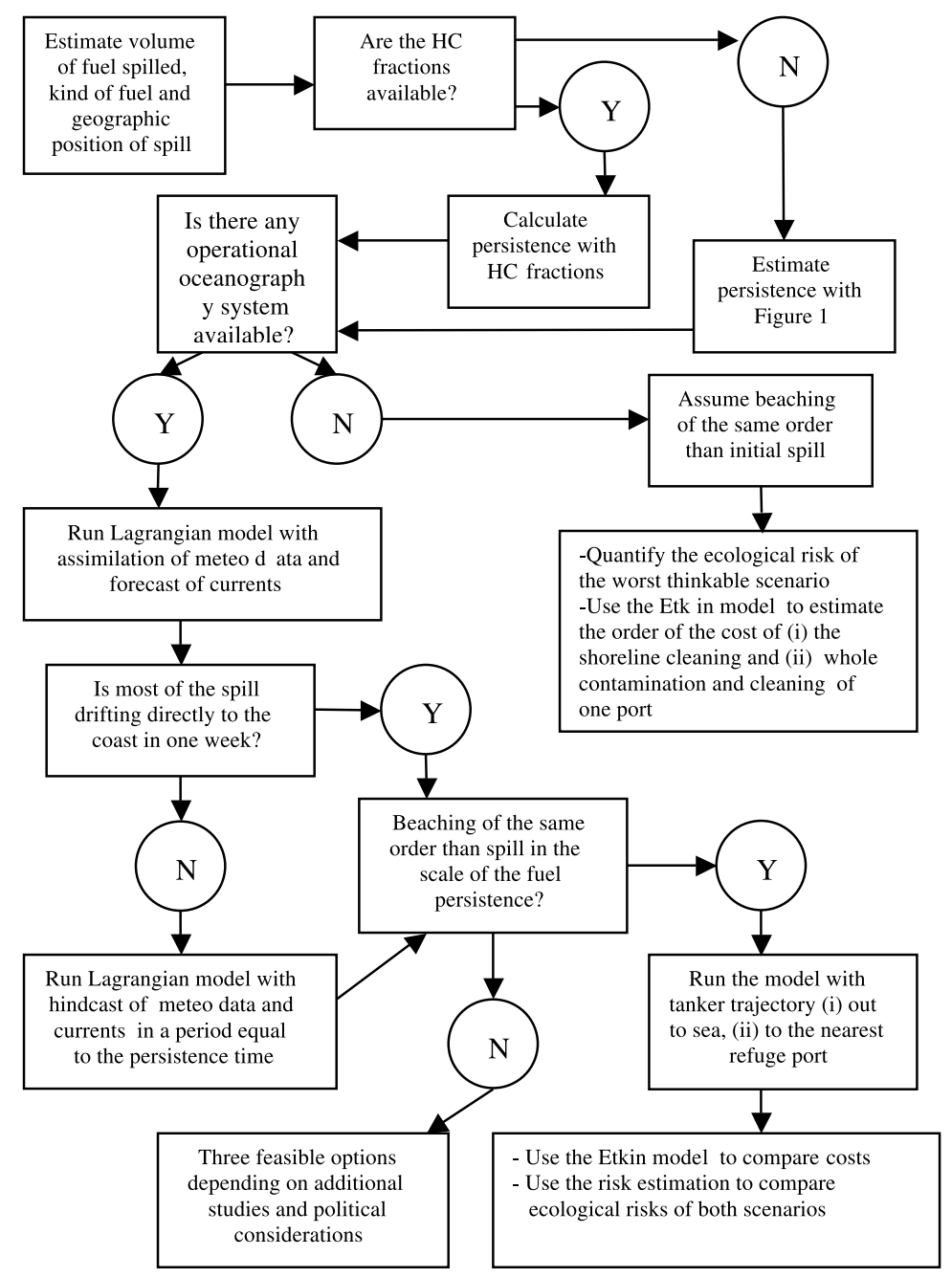

FIG. 8. - Decision Tree for an accident off the Galician coast.

tige case, the cleanup cost associated with a structural failure inside the port was quantified by Etkin model, but the costs associated with the possible occurrence of (i), (ii) and (v) were considered negligible in comparison with (iv). Fire and explosion are normally consequences of the presence of gas/vapour in the space between double hulls (Cavaye and Waibl, 2008) and are less probable in single-hulled ships, and much less probable with type IV oils than with oils of types I to III. For this reason, this kind of event was not considered in our case, even though its probability could be estimated in the way proposed by these authors. The order of magnitude of this probability is $6.3510^{-4}$ per ship per year (Cavaye and Waibl, 2008). The cost of the explosion itself can be minimized if the shelter dock is placed far from the commercial activity of the port. Then, the release produced after the fire is the main contributor to the cost and has been already taken into account in our estimation. Atmospheric contamination produced by fire could be a factor to be taken into account if large population densities are present in the surroundings of the port. A Coruña and Vigo ports are close to densely populated cities (246000 and 300000 inhabitants, respectively). The Ferrol-San Cibrao port is located in a somewhat less densely populated area (75000 inhabitants in Ferrol, $1 \mathrm{~km}$ away, 6000 inhabitants in Mugardos, $2 \mathrm{~km}$ away and 14000 inhabitants in Fene, $4 \mathrm{~km}$ away).

One of the conclusions of this study is the suitability of remodelling an outlying dock in the three above ports to include a tanker shelter facility. Of the three, Ferrol-San Cibrao is perhaps the preferred option, because the surroundings are less densely populated and the way into the Vigo port inlet is within a few kilometres of the National Park of the Atlantic Islands.

Figure 8 shows a decision tree that may guide the use of the methodology proposed if a disaster similar to the Prestige spill takes place in the future. The scheme is conceived to be applicable to any spill close to a coast, and not only to the Galician coast.

In accidents with oil of Groups I to III, an analysis of an actual spill based on the same principles as those set out in this paper, complemented by additional studies undertaken at the time, should be useful to inform 
the best decision to be taken. In this case, the Prestige accident does not give insight into the preferred choice. However, generic simulations could be undertaken to explore the situations in which the three alternatives (moving the tanker away, bringing it to port and not intervening) would be preferred.

In some particular cases, it could be possible to obtain estimates for fuel beaching that are much lower than the total spilled and show no difference in ecological risks in all the alternatives. In these cases, the decision should be based on non-technical reasons.

If no model were available in the first moments of an accident, a rough impact estimation could be obtained by using the Etkin model directly with conservative hypotheses on the shoreline length affected, as made in the "Costs and decision criteria" section, and this possibility has also been included in the decision tree.

The use of the kind of the proposed methodology in crisis situations makes it possible to use only scientific parameters to obtain a quick estimation of the order of magnitude of the costs associated with different management decisions. The final authority dealing with the management of the crisis thus has an objective basis for decision making.

\section{ACKNOWLEDGEMENTS}

This work has been realized with the partial support of TOSCA, project cofinanced by European Regional Development Fund, under Med Programme. We thank Dr. Luis Ferrer for providing the ROM hindcasts used in the Lagrangian simulations.

\section{REFERENCES}

Carracedo, P., S. Torres-López, M. Barreiro, P. Montero., C. F. Balseiro, E. Penabad, P. C. Leitao, V. Pérez-Muñuzuri. - 2006. Improvement of pollutant drift forecast system applied to the Prestige oil spills in Galicia Coast (NW of Spain): Development of an operational system. Mar. Pollut. Bull., 53: 350-360.

Cavaye, N. and G. Waibl. - 2008. The Development of a Risk Assessment Model to Compare Oil Spill Risk For Single and Double Hulled FPSOs. Proceedings of the 2008 International Oil Spill Conference, pp. 725-734.

CEDRE (Centre de Documentation, de Recherche et d'Expérimentations sur les Pollutions Accidentelles des Eaux). - 2002a. Les leçons techniques de l'Erika et autres accidents. Actes du colloque, Brest. Cedre. www.cedre.fr

CEDRE. - 2002b. Accidents. Prestige. www.cedre.fr

Daniel, P., P. Josse, P. Dandin, J.-M. Lefevre, G. Lery, F. Cabioch and V. Gouriou. - 2004. Forecasting the Prestige Oil Spills. In: Proceedings of the Interspill 2004 conference, Trondheim, Norway.

Elliott, A.J. - 1986. Shear diffusion, the spread of oil in the surface layers of the North Sea. Dtsch. Hydrogr. Z., 39: 113-137.

Etkin, D.S. - 1999. Estimating Cleanup Costs For Oil Spills. In: Proceedings of the 1999 International Oil Spill Conference, pp. 35-39.

Etkin, D.S. - 2000. Worldwide analysis of oil spill cleanup cost factors. Proceedings of the 23rd Arctic and Marine Oilspill Program Technical Seminar: 161-174.

EUROGOOS 2011. A definition and overview of Operational Oceanography can be found at: http://www.eurogoos.org/

Ferrer, L., A. Fontán, J. Mader, G. Chust, M. González, V. Valencia, A. Uriarte and M.B. Collins. - 2009. Low-salinity plumes in the oceanic region of the Basque Country. Cont. Shelf. Res. 29(8): 970-984.

González, M., A. Uriarte, R. Pozo and M. Collins. - 2006. The Prestige crisis: Operational oceanography applied to oil recovery, by the Basque fishing fleet. Mar. Pollut. Bull., 53: 369-374.

Irwin, R.J. (ed.). - 1997. Fuel Oil. In: Environmental Contaminants Encyclopedia. National Park Service, Fort Collins, Colorado, US.

Lenting, V. and C. Pratt C. - 2000. The New Zealand marine oil spill risk assessment 1998. In: New Zealand Petroleum Conference Proceedings, Auckland, New Zealand, 19-22 March 2000.

Loureiro, M.L., A. Ribasa, E. López and E. Ojea. - 2006. Estimated costs and admissible claims linked to the Prestige oil spill. Ecolog. Econ., 59: 48-63.

Marcos, M.J., A. Agüero, A. García-Olivares, B.D. Haupt and J.L. De Pablos. - 2004. Assessment of the behaviour of oil in the tanks of the "Prestige" in the Atlantic deep sea. Sci. Mar., 68: 307-315.

Martí Ezpeleta, A., E. García Martínez and A. Miragaya Veras. 1998. Rachas Máximas y Temporales de Viento en Galicia. Lurralde Investigación y Espacio, 21: 262-280.

Monnier, I. - 1994. The cost of oil spills after tanker incidents. Det Norske Veritas Research, Report $N^{\circ}$ 94-2024. Hovik, Norway.

Montero, P., J. Blanco, J.M. Cabanas, J. Maneiro, Y. Pazos, A. Moroño, C.F. Balseiro, P. Carracedo, B. Gómez, E. Penabad, V. Perez-Muñuzuri, F. Braunschweig, R. Fernades, P.C. Leitao and R. Neves. - 2003. Oil Spill Monitoring, Forecasting on the Prestige-Nassau accident. In: Proceedings 26th Arctic Marine Oil Spill Program (AMOP) Technical Seminar, 2: 1013-1029. Environment Canada, Ottawa, Canada.

Okubo, A. and S.A. Levin. - 2001. Diffusion and ecological problems. Springer.

Ruiz-Villarreal, M., C. González-Pola, G. Diaz del Rio, A. Lavin, P. Otero S. Piedracoba and J.M. Cabanas. - 2006. Oceanographic conditions in North and Northwest Iberia and their influence on the Prestige oil spill. Mar. Pollut. Bull., 53: 220-238.

Serret, P., X. Alvarez-Delgado, A. Bode and 419 other scientists from 32 universities and 6 research institutions. - 2003. Spain's Earth Scientists and the Oil Spill. Science, 299: 511.

Sotillo, M.G., E. Alvarez Fanjul, S. Castanedo, A.J. Abascal, J. Menendez, M. Emelianov, R. Olivella, E. García-Ladona, M. Ruiz-Villarreal, J. Conde, M. Gómez, P. Conde, A.D. Gutierrez and R. Medina. - 2008. Towards an operational system for oil-spill forecast over Spanish waters: Initial developments and implementation test. Mar. Pollut. Bull., 56: 686-703

Stolzenbach, K.D., O.S. Madsen, E.E. Adams, A.M. Pollack and C.K. Cooper. - 1977. A review and evaluation of basic techniques for predicting the behavior of surface oil slicks. MIT Report No. MITSG 77-8. Massachusetts Institute of Technology, Cambridge, MA.

Wene, J. - 2005. European and International Regulatory Initiatives Due to the Erika and Prestige Incidents. MLAANZ J., 19: 56-73.

White, I.C. and F.C. Molloy. - 2003. Factors that determine the cost of oil spills. In: International Oil Spill Conference 2003 ID\#83. The International Tanker Owners Pollution Federation Limited, London.

Wirtz, K.W., N. Baumberger, S. Adam and X. Liu. - 2007. Oil spill impact minimization under uncertainty: Evaluating contingency simulations of the Prestige accident. Ecolog. Econ., 61: 417-428.

Scient. ed.: J. Font.

Received October 12, 2009. Accepted February 4, 2011.

Published online May 2, 2011. 